\title{
The link between nutritional parameters and bone mineral density in women: results of a screening programme for osteoporosis
}

\author{
Theodora Lamprinoudi ${ }^{1}$, Elisa Mazza ${ }^{1}$, Yvelise Ferro ${ }^{1}$, Simona Brogneri ${ }^{1}$, Daniela Foti ${ }^{2}$, Elio Gulletta², \\ Maurizio locco ${ }^{3}$, Carmine Gazzaruso ${ }^{4,5}$, Stefano Romeo ${ }^{1,6}$, Arturo Pujia ${ }^{1}$ and Tiziana Montalcini $i^{1,7^{*}}$
}

\begin{abstract}
Background: A positive association between handgrip strength and bone mineral density was demonstrated, but not all the investigations confirmed these results. We conducted a screening programme for osteoporosis in a large cohort of postmenopausal women to investigate the relationship between handgrip strength, other nutritional parameters and bone density.

Methods: This investigation involved 1,300 white volunteers. All participants underwent a bone mineral density evaluation at the heel and a handgrip strength measurement.

Results: The mean T-score value was $-1.15 \pm 1$; a total of 181 participants reported at least one osteoporotic fracture. In the univariate analysis, both handgrip strength and body mass index were associated with the T-score value. Adjustment for confounding factors confirmed this relationship showing, in the multivariate analysis, that the body mass index was positively correlated to the T-score $(B=0.034 ; p=0.001)$ and, in the logistic regression analysis, that handgrip strength was associated with the presence of osteoporosis $(P=0.005)$.
\end{abstract}

Conclusion: Both body mass index and handgrip strength were strongly correlated to bone mineral density, assessed with ultrasound, suggesting a possible key role as bone disease predictors.

\section{Introduction}

Aging per se is a well-known risk factor for osteoporosis, frailty, sarcopaenia and atherosclerosis [1,2]. The mechanisms that underlie the onset of these conditions are still unclear, however, hormonal alterations, which are the main age-associated changes, are probably the key factors, also influencing comorbidity [3]. Furthermore, the increased synthesis and secretion of adipokines and other factors of inflammation associated with aging and menopause could contribute to the development of chronic diseases [4]. Comorbidity must be taken into consideration in menopause and aging, especially to develop more effective treatments to ensure well-being during the postmenopausal period. In this regard, it has been shown that handgrip strength and bone mineral density (BMD)

\footnotetext{
* Correspondence: tmontalcini@unicz.it

${ }^{1}$ Clinical Nutrition Unit, Department of Medical and Surgical Science, University Magna Grecia, Catanzaro, Italy

7University Magna Grecia, Viale S. Venuta, 88100 Catanzaro, Italy

Full list of author information is available at the end of the article
}

are positively associated [5-13] suggesting a connection between sarcopaenia and osteoporosis. However, not all the investigations confirmed this result [14-18]. Consequently, we conducted a screening programme for osteoporosis in a large cohort of women to investigate the relationship between handgrip strength and BMD assessed at the heel, as well as the relationship between the ultrasound and dual energy X-ray absorptiometry (DXA) BMD assessment in postmenopausal women.

\section{Materials and methods}

This survey was conducted from May 2012 to May 2013 at the University Hospital of Catanzaro, Italy, and involved 1,300 consecutively white volunteers of both genders. All subjects aged over 45 living in the city of Catanzaro were invited by newspapers ads to participate in the study. All participants underwent a brief interview to provide information about current and past physical exercise activity, use of medications, age at menopause and history of fractures. Pathological or high-energy fractures and fractures 
in sites not commonly associated with osteoporosis were not considered in the statistical analysis. Men were also excluded from statistical analysis. Postmenopausal status was defined as the presence of a serum follicle-stimulating hormone (FSH) level of over $40 \mathrm{IU} / \mathrm{l}$ (if available) or no natural menses for at least 1 year. All participants underwent a BMD and handgrip strength measurement. We obtained their informed consents to participate in the study. The investigation conforms to the principles outlined in the Declaration of Helsinki.

\section{Handgrip strength measurement}

The handgrip strength was measured by dieticians previously trained in the technique. Subjects unable to perform the strength measurements for any cause were excluded from the statistical analysis. The handgrip strength was measured using an hydraulic hand dynamometer (Hersteller/manufactures; SAEHAN Corporation, Masan- Korea; Distributor Rehaforum Medical GmbH, Elmshorn- Germany) having less than 10\% variation in results for various grip positions. Subjects were seated, with their elbows flexed at $90^{\circ}$ and supported at the time of the measurement. Dieticians collected three measurements from each hand, and used the mean value in all analyses. During the measurement, we asked the subject to grip the dynamometer with maximum strength, and to hold the grip for at least three seconds [19-21]. Handgrip strength is registered as maximum kilograms of strength applied during the registration.

\section{Ultrasound BMD assessment}

Quantitative ultrasound (Lunar Achilles Insight, GE Medical Systems) was used to measure the speed of sound (metres per second) and broadband ultrasound attenuation (decibels per megahertz) of the heel. In cases of a previous fracture within the lower extremity, only the opposite calcaneus was measured. T-score was derived from the value of broadband ultrasound attenuation and expressed as the number of SDs from the mean value of a control gender-matched population [22]. The $\mathrm{T}$-scores are reported as the number of standard deviations below the young adult mean (normal, > -1 ; osteopaenia, -1 to -2.49 ; osteoporosis, $\leq-2.5$ ) [22]. The device was calibrated daily in accordance with the manufacturer's recommendations. The same operator took all the measurements. Short-term in vivo precision was established on the basis of repeated measurements in 10 healthy women. The coefficient of variation (CV\%) was calculated using the following formula: CV\% _ (SD/mean) 100; the percentage value was: $4 \%$ for broadband ultrasound attenuation and $1.2 \%$ for speed of sound.

\section{DXA assessment}

Postmenopausal women with a high risk of fractures $[5,14]$ who also gave their informed consent underwent a concomitant BMD of the lumbar spine and left femur evaluation by DXA. BMD was expressed as the amount of mineral ( $\mathrm{g}$ ) divided by the area scanned $\left(\mathrm{cm}^{2}\right)$. All DXA measurements were performed by the same densitometer (Lunar DPX BRAVO, GE Medical Systems, Madison WI) and operator. Low BMD was defined according to the T-score, calculated on the basis of the normal reference values. The T-scores are reported as the number of standard deviations below the young adult mean (normal, > -1 ; osteopaenia, -1 to -2.49 ; osteoporosis, $\leq-2.5$ ) while the Z-score was the number of standard deviations in comparison to women of the same age [22].

The instrument was calibrated every day in accordance with the manufacturer's recommendations. The in vivo precision was established on the basis of repeated measurements in 40 women and was $<1 \%$.

\section{Statistical analysis}

Data are reported as mean \pm standard deviation (SD). A chi square test was performed to analyse the prevalence. A $T$-test was performed to compare the means between women with and without osteoporosis. The Pearson correlation was used to identify the variables correlated to the T-score (the number of SDs) obtained from the value of broadband ultrasound attenuation (BUA T-score) given that the continuous variables were normally distributed. The Multivariate linear regression analysis was used to test the association for confounding variables selected from univariate analysis having a $\mathrm{p}<0.1$. Furthermore, a logistic regression analysis was used, considering the presence of osteoporosis as a dependent variable, and including, as independent variables, all those significantly different in the $T$-test and those associated with BUA T-score in the univariate analysis. The area under the receiver operating characteristic (ROC) curve was used to analyse the capacity of the ultrasound screening test on the heel, to predict the normal BMD with DXA evaluation in a group of postmenopausal women receiving a concomitant DXA evaluation.

Significant differences were assumed to be present at $\mathrm{p}<0.05$ (two-tailed). All comparisons were performed using SPSS 20.0 for Windows (S. Wacker Drive, Chicago, Illinois 60606, USA).

\section{Results}

Complete data were obtained from 1,058 women. The mean BUA T-score was $-1.15 \pm 1.2$; 181 participants experienced at least one osteoporotic fracture [specifically $\mathrm{n}=94$ of the wrist, $\mathrm{n}=57$ of the lower limbs (including femur neck), $n=39$ of the vertebrae and ribs]. None of 
Table 1 Demographical and clinical characteristics of the whole population

\begin{tabular}{|c|c|c|}
\hline Variables & Mean & SD \\
\hline Age & 57,2 & 10,4 \\
\hline Age at menopause & 48,9 & 5,1 \\
\hline BMl & 27,5 & 4,9 \\
\hline BUA T-score & $-1,15$ & 1,2 \\
\hline DXA T-score (femur)* & $-1,74$ & 0,9 \\
\hline DXA T-score (vertebrae)* & $-1,92$ & 1,1 \\
\hline Handgrip (kg) & 24,16 & 6,1 \\
\hline \multicolumn{3}{|l|}{ Prevalences } \\
\hline Menopausal \% & 90 & \\
\hline Normal BMD \% & 39 & \\
\hline Osteopenia \% & 45,5 & \\
\hline osteoporosis \% & 16 & \\
\hline Diabetes \% & 7 & \\
\hline hyperlipidemia \% & 17 & \\
\hline Hypertension \% & 40,4 & \\
\hline With CVD \% & 16,7 & \\
\hline Total fractures \% & 26 & \\
\hline \multicolumn{3}{|l|}{ Medications } \\
\hline Calcium \% & 5,7 & \\
\hline Vitamin D \% & 8,5 & \\
\hline Antiresorptive agents \% & 6,4 & \\
\hline
\end{tabular}

the participants had received medication for rheumatoid arthritis or oral steroids for a prolonged period of time. The prevalence of osteoporosis [22] was $16 \%$ and $90 \%$ were postmenopausal. The characteristics of the whole population are shown in Table 1 . Table 2 shows the factors associated with the BUA T-score. The Multivariate linear regression analysis (Table 3 ) showed that only age and BMI were correlated to the BUA T-score; Handgrip Strength did not remain in correlation in this analysis. The comparison between women with and without osteoporosis (Table 4) showed a significant difference in age, Handgrip Strength, and in the age of menopause. The logistic regression analysis showed that age and Handgrip Strength were correlated to the BUA T-score (Table 5). However, when we divided the population according to the presence of fractures, women with fractures had a higher age and a lower BMD than those

Table 2 Univariate analysis- Pearson correlation

\begin{tabular}{llllll}
\hline Factors & & Age & $\begin{array}{l}\text { Age at } \\
\text { menopause }\end{array}$ & Handgrip & BMI \\
\hline Variable & $\begin{array}{l}\text { Pearson } \\
\text { correlation }\end{array}$ & $-0,358$ & 0,025 & 0,201 & 0,115 \\
US T- score & $p$ & $<0,001$ & 0,487 & $<0,001$ & 0,009 \\
\hline
\end{tabular}

Table 3 Multivariate Linear regression analysis- factors correlated to BUA T-score

\begin{tabular}{llllll}
\hline Variables & B & SE & beta & t & p \\
\hline Age & $-0,046$ & 0,006 & $-0,335$ & $-8,092$ & $<0,001$ \\
BMI & 0,034 & 0,010 & 0,137 & 3,318 & 0,001 \\
\hline Excluded variable: Handgrip $=$ beta 0,$052 ;$ & $\mathbf{p}=0,245$.
\end{tabular}

without fractures $(\mathrm{p}<0.001)$, while there was not a significant difference in the anthropometric parameters between the two groups (data not shown). A group of 62 postmenopausal women underwent a concomitant DXA evaluation. In these participants the area under the ROC curve for BUA T-score to predict DXA measurement was 0.705 ( $\mathrm{SE}=0.076$; p 0.020). The BUA T-score equal to -3 achieved acceptable sensitivity (77\%), but the corresponding specificity remained poor (50\%); while a BUA T-score equal to -2.7 achieved a minor sensitivity (58\%), with a satisfactory corresponding specificity (72\%).

\section{Discussion}

From this survey we obtained several relevant data: first we found, in this geographical area, a prevalence of osteoporosis [22] of $16 \%$, comparable to other investigations, and about half of population had osteopaenia, but less than $7 \%$ of screened women were medically treated for osteoporosis, in contrast with the women described in the other studies [23]. Another important aspect of this study was that BUA T-score was positively correlated to some nutritional parameters like Handgrip Strength and BMI (Table 2) also after adjustment for confounding factors in the multivariate and logistic regression analysis (Tables 3 and 5) suggesting the importance of measuring them to predict the low BMD.

These findings are very important since it is well accepted that the early phases of osteoporosis present little or no symptoms thus it is often difficult to identify women needing treatment for osteoporosis before their first fracture. These results may suggest the importance of promoting screening programmes using a non-invasive evaluation

Table 4 Comparison between women with and without osteoporosis

\begin{tabular}{|c|c|c|c|c|c|}
\hline \multirow[b]{2}{*}{ Variables } & \multicolumn{2}{|c|}{$\begin{array}{l}\text { Without } \\
\text { osteoporosis }\end{array}$} & \multicolumn{2}{|c|}{$\begin{array}{l}\text { With } \\
\text { osteoporosis }\end{array}$} & \multirow[t]{2}{*}{ p } \\
\hline & Mean & SD & Mean & SD & \\
\hline \multicolumn{6}{|l|}{$t$-test } \\
\hline Age (ys) & 56,40 & 10,104 & 58,78 & 11,007 & 0,001 \\
\hline Age at menopause (ys) & 49,09 & 4,977 & 48,13 & 5,559 & 0,020 \\
\hline Hand grip strenght (kg) & 24,57 & 6,130 & 22,94 & 5,940 & $<0,001$ \\
\hline BMI & 27,3232 & 4,83373 & 28,1585 & 5,58306 & 0,109 \\
\hline \multicolumn{6}{|l|}{ Chi square test } \\
\hline Total fractures (\%) & 24 & & 37 & & $<0,001$ \\
\hline
\end{tabular}


Table 5 Logistic regression analysis - factors correlated with Osteoporosis

\begin{tabular}{lllll}
\hline & $\mathbf{B}$ & SE & $\mathbf{p}$ & $\exp (\mathbf{B})$ \\
\hline Age & 0,049 & 0,019 & 0,011 & 1,050 \\
Age at menopause & $-0,027$ & 0,025 & 0,284 & 0,973 \\
Handgrip & $-0,054$ & 0,027 & 0,050 & 0,948 \\
\hline
\end{tabular}

of $\mathrm{BMD}$ for the early identification of women with a low BMD $[24,25]$.

Furthermore, our results confirm the role of BMI and muscular strength as key indices which may be useful as predictors for osteoporosis. The decline in muscle strength is considered a consequence of aging [26] due to the degeneration of muscle fibres. This was confirmed in our investigation, since both women with and without osteoporosis had a lower handgrip strength value compared to younger women evaluated in a previous study [21]. In addition, it has been shown that there are substantial inter-individual differences in the rate of strength decline, due to variation in genetics and environmental influences [27]. In this context, it is not clear if there is a site-specific effect of muscular strength on BMD [28]. Indeed, it has been shown that quadriceps strength can explain a large part of the association between lean mass and BMD at the femoral neck site but not at the lumbar spine site [28]. Furthermore, inflammation, hormonal changes and some chronic diseases could be determinants in the development of osteoporosis $[29,30]$. At this moment, the specific role of regional muscular strength on BMD is not fully clear. However, our results could contribute to add further information to this issue. Handgrip strength is probably a good index of frailty and also of some nutrient deficiencies, thus, the link with a low BMD is plausible [31]. In this study we showed a positive relationship between BMD and BMI. This concurs with other studies which showed higher BMD in obese women than in normalweight ones, since obesity exerts a positive effect on BMD due to mechanical load and/or for conversion of androgen into oestrogen in adipose tissue [32].

Our results also raise concerns over the cost-effectiveness of such a screening intervention. Of course fracture prevention at an early stage of osteoporosis is preferable, and an osteoporosis screening programme with US may be considered more cost-effective in comparison to DXA assessment. We believe that quantitative ultrasound of the heel, in combination with the risk factors for osteoporosis assessment, is an acceptable option to DXA measurements in osteoporosis detection.

There are limitations to our study in that it was conducted in a single geographical area. Furthermore, we did not include specific measures of physical activities.

\section{Conclusion}

In our survey, we showed that BMI and handgrip strength were strongly correlated to BMD measured with quantitative ultrasound of the heel. Despite the appreciable prevalence of total fractures in the women with osteoporosis less than half of them were medically treated in secondary prevention. Since the correlation between BMD assessed with US and that measured with DXA in postmenopausal women, our results show that there is still a need to promote screening programmes to identify those with low BMD with the aim of reducing the recurrence of fractures.

\section{Summary}

We conducted a screening programme for osteoporosis in a large cohort of postmenopausal women to investigate the relationship between handgrip strength and bone mineral density assessed at the heel. Furthermore, we studied the relationship between bone density assessed with ultrasound and that assessed with dual energy X-ray absorptiometry.

\section{Competing interest \\ The authors declare that they have no competing interest.}

\section{Authors' contributions}

TM and AP were responsible for study design, data analysis, manuscript writers; SR contributed to interpretation of the data, TL was responsible for enrollment, BMD evaluation and integrity of data; EM, YF, SB performed anthropometric measurement, data collection; DF, EG, MI and CG revised study design, manuscript and approved final version. All authors read and approved the final manuscript.

\section{Acknowledgments}

We are grateful to "University Magna Graecia Foundation" for the logistical support and the help in the manuscript revision.

\section{Author details}

${ }^{1}$ Clinical Nutrition Unit, Department of Medical and Surgical Science, University Magna Grecia, Catanzaro, Italy. ${ }^{2}$ Clinical Pathology Unit, Department of Health Science, University Magna Grecia, Catanzaro, Italy. ${ }^{3}$ Physiatry Unit, Department of Medical and Surgical Science, University Magna Grecia, Catanzaro, Italy. ${ }^{4}$ Diabetes, Endocrine-metabolic Dis. Cardiovasc. Prevention Unit, Clinical Inst. "Beato Matteo", Vigevano, Italy. ${ }^{5}$ Department of Internal Medicine, I.R.C.C.S. Policlinico San Donato Milanese, San Donato Milanese, Italy. ${ }^{6}$ Department of Molecular and Clinical Medicine, Sahlgrenska Center for Cardiovascolar and Metabolic Research, University of Gothenburg, Göteborg, Sweden. ${ }^{7}$ University Magna Grecia, Viale S. Venuta, 88100 Catanzaro, Italy.

Received: 6 December 2013 Accepted: 14 February 2014 Published: 19 February 2014

\section{References}

1. Verbrugge LM, Jette AM: The disablement process. Soc Sci Med 1994, 38:1-14.

2. Cigolle C, Langa KM, Kabeto MU, Tian Z, Blaum CS: Geriatric conditions and disability: the Health and Retirement Study. Ann Intern Med 2007, 147:156-164.

3. Horstman AM, Dillon EL, Urban RJ, Sheffield-Moore M: The role of androgens and estrogens on healthy aging and longevity. J Gerontol A Biol Sci Med Sci 2012, 67:1140-1152. doi: 10.1093/gerona/gls068.

4. Kong APS, Chan NN, Chan JCN: The role of adipocytokines and neurohormonal dysregulation in metabolic syndrome. Curr Diabetes Rev 2006, 2:397-407 
5. Bauer DC, Browner WS, Cauley JA, Orwoll ES, Scott JC, Black DM, Tao JL, Cummings SR: Factors associated with appendicular bone mass in older women. The Study of Osteoporotic Fractures Research Group. Ann Intern Med 1993, 118:657-665.

6. Bevier WC, Wiswell RA, Pyka G, Kozak KC, Newhall KM, Marcus R: Relationship of body composition, muscle strength, and aerobic capacity to bone mineral density in older men and women. J Bone Miner Res 1989, 4:421-432.

7. Di Monaco M, Di Monaco R, Manca M, Cavanna A: Handgrip strength is an independent predictor of distal radius bone mineral density in postmenopausal women. Clin Rheumatol 2000, 19:473-476.

8. Foley KT, Owings TM, Pavol MJ, Grabiner MD: Maximum grip strength is not related to bone mineral density of the proximal femur in older adults. Calcif Tissue Int 1999, 64:291-294.

9. Osei-Hyiaman D, Ueji M, Toyokawa H, Takahashi H, Kano K: Influence of grip strength on metacarpal bone mineral density in postmenopausal Japanese women: a cross sectional study. Calcif Tissue Int 1999, 64:263-266

10. Proctor DN, Melton LJ, Khosla S, Crowson CS, O'Connor MK, Riggs BL: Relative influence of physical activity, muscle mass and strength on bone density. Osteoporos Int 2000, 11:944-952.

11. Rikkonen T, Sirola J, Salovaara K, Tuppurainen M, Jurvelin JS, Honkanen R, Kröger $\mathrm{H}$ : Muscle strength and body composition are clinical indicators of osteoporosis. Calcif Tissue Int 2012, 91:131-138. doi:10.1007/s00223-0129618-1.

12. Sinaki M, Wahner HW, Offord KP: Relationship between grip strength and related regional bone mineral content. Arch Phys Med Rehabil 1989, 70:823-826.

13. Snow-Harter $C$, Bouxsein M, Lewis B, Charette $S$, Weinstein $P$, Marcus R: Muscle strength as a predictor of bone mineral density in young women. J Bone Miner Res 1990, 5:589-595.

14. Glynn NW, Meilahn EN, Charron M, Anderson SJ, Kuller LH, Cauley JA: Determinants of bone mineral density in older men. J Bone Miner Res 1995, 10:1769-1777.

15. Van Pottelbergh I, Goemaere S, Nuytinck L, De Paepe A, Kaufman JM: Association of the type I collagen alpha1 $\mathrm{Sp} 1$ polymorphism, bone density and upper limb muscle strength in community dwelling elderly men. Osteoporos Int 2001, 12:895-901.

16. Taafe DR, Cauley JA, Danielson M, Nevitt MC, Lang TF, Bauer DC, Harris TB: Race and sex effects on the association between muscle strength, soft tissue, and bone mineral density in healthy elders: the health, aging and body composition study. J Bone Miner Res 2001, 16:1343-1352.

17. Chan HHL, Lau EMC, Woo J, Lin F, Sham A, Leung PC: Dietary calcium intake, physical activity and the risk of vertebral fracture in Chinese. Osteoporos Int 1996, 6:228-232.

18. Ling $X$, Cummings SR, Mingwei $Q$, Xihe $Z$, Xioashu C, Nevitt M, Stone K: Vertebral fractures in Beijing, China: the Beijing Osteoporosis Project. J Bone Miner Res 2000, 15:2019-2025.

19. Budziareck MB, Pureza Duarte RR, Barbosa-Silva MC: Reference values and determinants for handgrip strength in healthy subjects. Clin Nutr 2008, 27:357-362. doi: 10.1016/j.clnu.2008.03.008.

20. Rantanen T, Harris T, Leveille SG, Visser M, Foley D, Masaki K, Guralnik JM: Muscle strength and body mass index as long-term predictors of mortality in initially healthy men. J Gerontol A Biol Sci Med Sci 2000 55:M168-M173.

21. Montalcini T, Migliaccio V, Ferro Y, Rotundo S, Mazza E, Liberato A, Pujia A: Reference values for handgrip strength in young people of both sexes. Endocrine 2012, 43:342-345. doi: 10.1007/s12020-012-9733-9.

22. World Health Organization: Assessment of fracture risk and its application to screening for postmenopausal osteoporosis. Report of a WHO Study Group. World Health Organ Tech Rep Ser 1994, 843:1-129.

23. Morales-Torres J, Gutiérrez-Ureña S, Osteoporosis Committee of Pan-American League of Associations for Rheumatology: The burden of osteoporosis in Latin America. Osteoporos Int 2004, 15:625-632.

24. Chiang A, Jones J, Humphreys J, Martin C: Osteoporosis-diagnosis and treatment in a general practice population. Aust Fam Physician 2006, 35:166-168.

25. Haentjens P, Magaziner J, Colón-Emeric CS, Vanderschueren D, Milisen K, Velkeniers B, Boonen S: Meta-analysis: excess mortality after hip fracture among older men and women. Ann Intern Med 2010, 152:380-390.
26. Forrest KY, Zmuda JM, Cauley JA: Patterns and correlates of muscle strength loss in older women. Gerontology 2007, 53:140-147.

27. Tiainen K, Sipila S, Alen M, Heikkinen E, Kaprio J, Koskenvuo M, Tolvanen A, Pajala S, Rantanen T: Heritability of maximal isometric muscle strength in older female twins. J Appl Physiol 2004, 96:173-180.

28. Blain H, Vuillemin A, Teissier A, Hanesse B, Guillemin F, Jeandel C: Influence of muscle strength and body weight and composition on regional bone mineral density in healthy women aged 60 years and over. Gerontology 2001, 47:207-212.

29. Montalcini T, Romeo S, Ferro Y, Migliaccio V, Gazzaruso C, Pujia A: Osteoporosis in chronic inflammatory disease: the role of malnutrition. Endocrine 2012, 43:59-64.

30. Montalcini T, Emanuele V, Ceravolo R, Gorgone G, Sesti G, Perticone F, Pujia $A$ : Relation of low bone mineral density and carotid atherosclerosis in postmenopausal women. Am J Cardiol 2009, 94:266-269.

31. Bouillon K, Kivimaki M, Hamer M, Sabia S, Fransson El, Singh-Manoux A, Gale CR, Batty GD: Measures of frailty in population-based studies: an overview. BMC Geriatr 2013, 21:13-64. doi: 10.1186/1471-2318-13-64.

32. Stewart KJ, Deregis JR, Turner KL, et al: Fitness, fatness and activity as predictors of bone mineral density in older persons. J Intern Med 2002, 2:381-388.

doi:10.1186/1479-5876-12-46

Cite this article as: Lamprinoudi et al:: The link between nutritional parameters and bone mineral density in women: results of a screening programme for osteoporosis. Journal of Translational Medicine 2014 12:46.

\section{Submit your next manuscript to BioMed Central and take full advantage of:}

- Convenient online submission

- Thorough peer review

- No space constraints or color figure charges

- Immediate publication on acceptance

- Inclusion in PubMed, CAS, Scopus and Google Scholar

- Research which is freely available for redistribution 